\title{
Nailing treatment in bone transport complications
}

\author{
C. Biz $\cdot$ C. Iacobellis
}

Received: 5 June 2013/Accepted: 18 July 2014/Published online: 24 July 2014

(C) The Author(s) 2014. This article is published with open access at Springerlink.com

\begin{abstract}
A series of cases of reamed intramedullary nailings carried out after complications in regenerated bone and docking site had occurred in bone transport is presented here. Nine patients (femur $=5$; tibia $=4$ ) had treatment with resection after open fractures or infection and underwent bone transport. The mean length of regenerated bone was $9.5 \mathrm{~cm}$ (range 6-18 cm). After bone transport, the fixator remained in place for a mean period of 12.8 months (range 8-24 months). In six cases (femur 4; tibia 2), the thickness of the cortical wall of the regenerate column was insufficient, and in two of these, there was, in addition, nonunion of the docking site. In the two tibial cases, nailing was carried out shortly after the fixator had been removed and after refracture of the regenerated bone had occurred due to insufficient cortical thickness. In one femur, nailing was carried out for nonunion of the docking site. Follow-up involved clinical and X-ray checks. The mean follow-up was 3.9 years (range 2-6 years). In all cases, union and with complete corticalization of the regenerate column was observed at an average 6 months after nailing (range 4-11 months). Infection occurred in one tibia 4 months after nailing. The infection was treated with antibiotics, and the nail was subsequently removed. We conclude that nailing is a potential solution for regenerated bone and docking site problems but, if used after prolonged periods of external fixation, may necessitate antibiotic therapy for at least 10 days after the fixator has been removed.
\end{abstract}

C. Biz $\cdot$ C. Iacobellis $(\bowtie)$

Orthopaedic Clinic, Department of Surgery, Oncology and

Gastroenterology DiSCOG, University of Padua,

Via Giustiniani 2, 35128 Padua, Italy

e-mail: claudio.iacobellis@unipd.it
Keywords Bone transport - Distraction osteogenesis . External fixator $\cdot$ Intramedullary nailing

\section{Introduction}

Bone transport for segmental resections in the treatment for infected nonunion, osteomyelitis, or after bone loss in open fractures remains a major undertaking for orthopedic surgeons [1-4]. For long-bone diaphyseal defects larger than $5 \mathrm{~cm}$, with or without a soft-tissue defect, specialized management is needed [5]. The use of vascularized bone grafts [6, 7], allograft bone transplantation, or bone transport by an external fixator alone or over an intramedullary nail has been reported in [8-10]. Bone transport with a circular or monolateral external fixator represents a standard method for managing lower limb bone defects and for limb lengthening [11-14]. These methods induce two biological processes: distraction osteogenesis, the new production of bone from a corticotomy, and transformational osteogenesis, where the mechanical stimulation of an abnormal bony interface regenerates normal bony continuity and achieves consolidation [15, 16]. Further, the regenerated bone formed by bone transport is mechanically stronger to that formed by bone grafting but there is a risk of refracture after frame removal [17]. Distraction osteogenesis by the Ilizarov technique [18-20], subsequently modified by Cattaneo et al. [21], has been used successfully in all long bones since its introduction [17, 22-26]. In contrast, bone transport using a monolateral external fixator achieves a similar result through distraction of callus (callotasis) that is obtained from a subperiosteal osteotomy [27]. Compared with a circular frame, this device has the advantage of being lighter and a simpler application. There is also less soft-tissue transfixation by pins, thereby 
allowing early physical exercise and partial weight-bearing [28]. Use of hydroxyapatite-coated pins decreases pin siterelated problems $[9,29]$.

Bone transport carries advantages of minimal soft-tissue trauma, almost limitless reconstruction of bone defects and elimination of donor site morbidity [30,31]. The process of bone transport using an external fixator alone is still a lengthy and uncomfortable process. It is a labor-intensive surgical procedure and subjects to many complications with considerable treatment times [32-36]. Despite the versatility of distraction osteogenesis, both patients and orthopedic surgeon are prompted to remove the external fixator early to decrease discomfort and complications [37] of which the most frequent are nonunion at the docking site [38], fracture of regenerated bone due to the lack of internal stabilization, failure of distraction osteogenesis, and recurring infection [39, 40]. Simpson and Kenwright [41] report a fracture rate of $9.4 \%$ in a series of 180 lengthening segments; O'Carrigan [42] reports an $8 \%$ fracture rate in 650 patients with 986 lengthening segments, and Danziger [43] had refracture of the femur in 6 of 18 patients. Lavini [38] had axial deviation in $17.6 \%$ in a series of 17 cases. In our previous study of 100 consecutive cases of bone transport using the Ilizarov method, we found $1 \%$ refracture of the newly formed bone segment of the tibia, $17 \%$ nonunion at the docking site in 10 femurs and 7 tibias, $10 \%$ bone transport arrest due to the failure of distraction osteogenesis in 2 femurs and 8 tibias, and $4 \%$ of cases had recurring infection [22]. Furthermore, paresthesiae $(9 \%)$ [32, 44], angulation, and deformity of the newly formed bone column $(2-17 \%)$ [22, 38, 44], and neighboring joint contractures due to increased soft-tissue tension and joint stiffness (10-28\%) [22, 44], are encountered frequently during lengthening and bone transport.

One solution to some of these complications is the insertion of an intramedullary nail in order to support the regenerated bone during the consolidation phase and facilitate the removal of the external fixator after the distraction phase of lengthening. However, intramedullary nailing after bone transport with a circular or monolateral external fixator is still controversial as there is a risk of infection. Specifically, when combining external and internal fixation, the risk of deep infection has been reported between 3 and $15 \%$ [45, 46]. Other methods employed to shorten the external fixation treatment period have been described: docking site stimulation with autogenous bone graft, bone marrow injection, electric or magnetic field stimulation, ultrasound stimulation, and the use of bone growth stimulating factors [47].

This retrospective study was carried out on a sample of patients treated with reamed intramedullary nailing after bone transport with the aim of assessing the evolution of union and the incidence of infection and major complications after surgery.

\section{Materials and methods}

This is a retrospective review of a case series. All subjects participating in this study were counselled over the risks and benefits of the procedure; informed consent for inclusion in this retrospective case series was obtained. Between 2006 and 2010, nine patients (eight males, one female; average age 35.5 years; range 25-57) underwent bone transport for bone loss after open fractures and infection. All patients had bone defects of $>5 \mathrm{~cm}$ after resection and debridement. There were no specific exclusion criteria. Five femurs and four tibias were involved. In all cases, samples were taken for culture. These included no fewer than four swabs both before and during surgery. The cause of infection was identified as Staphylococcus aureus in six cases and Pseudomonas aeruginosa in 3. Subsequent antibiotic therapy was carried out, according to the culture and sensitivity results, for a minimum 6-week period or until the erythrocyte sedimentation rate and C-reactive protein level had returned to normal [48].

Six patients were treated using the Ilizarov circular fixator (Amplimedical s.p.a, Milan, Italy) and 3 with a monolateral rail fixator (Limb Reconstruction System Orthofix SRL, Verona, Italy). The types of transport through healthy tissue were descending (proximal-distal) in two cases (femurs), ascending in four cases (one femur, three tibias), double transport in two femurs (with mid-diaphyseal contact of transported bone ends at the docking site from proximal and distal metaphyseal osteotomies), and in one tibia (twin transport from a double proximal osteotomy). The mean length of regenerated bone was $9.5 \mathrm{~cm}$ (range 6-18). At the end of transport, the fixator was kept in place for a mean period of 12.8 months (range 8-24). In all cases, the docking site was exposed, the interposed tissue was removed, and if small residual gaps were seen between the two bone ends, cancellous bone was taken from the ipsilateral iliac crest and grafted. We observed spontaneous healing of the skin defects at the docking site; plastic surgical cover was not required. Reaming and nailing (Synthes nail) were carried out in six cases (four femurs, two tibias; cases $1-4,6,9)$ for which the thickness of the cortical wall of the regenerated bone was deemed insufficient (Fig. 1) and removal of the fixator would have created a high risk of fracture. In two of these six patients (cases 4 and 9), nonunion of the docking site was diagnosed additionally. In another patient (case 3; Fig. 2), a bony bridge had formed between the intended docking site and transport segment causing an arrest of transport and varus and procurvatum deformity of the regenerated bone. 

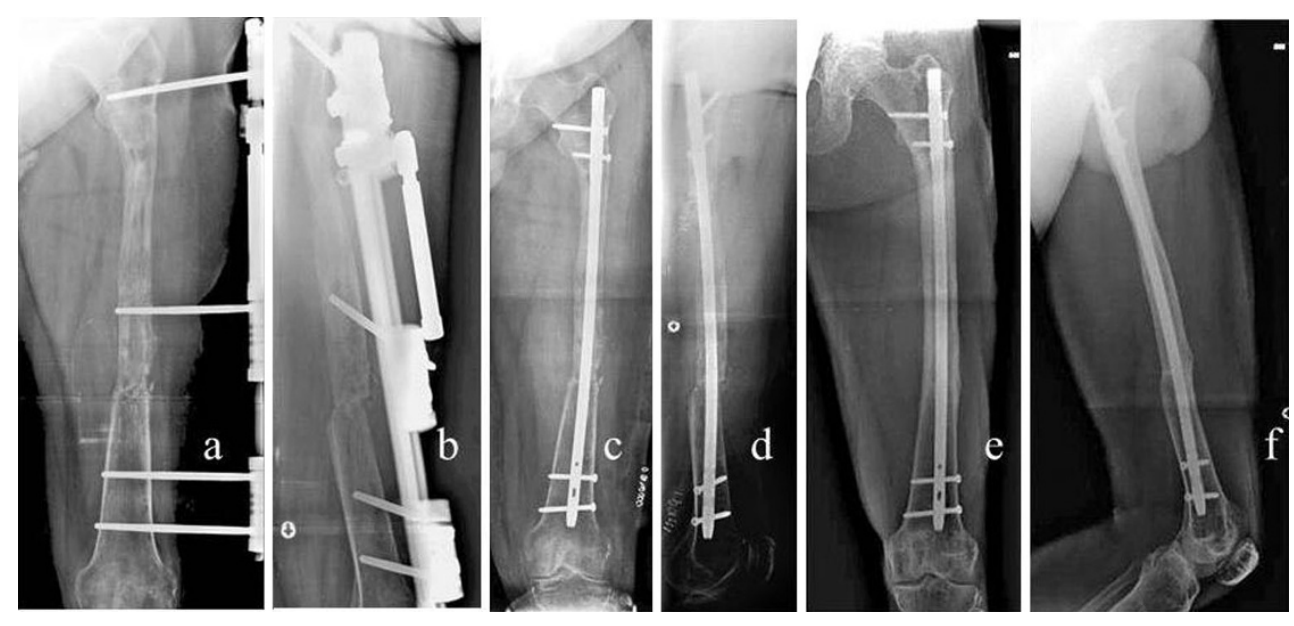

Fig. 1 Case 2: a, b preoperative X-ray, c, d postoperative checkup, e, f follow-up 5 years later
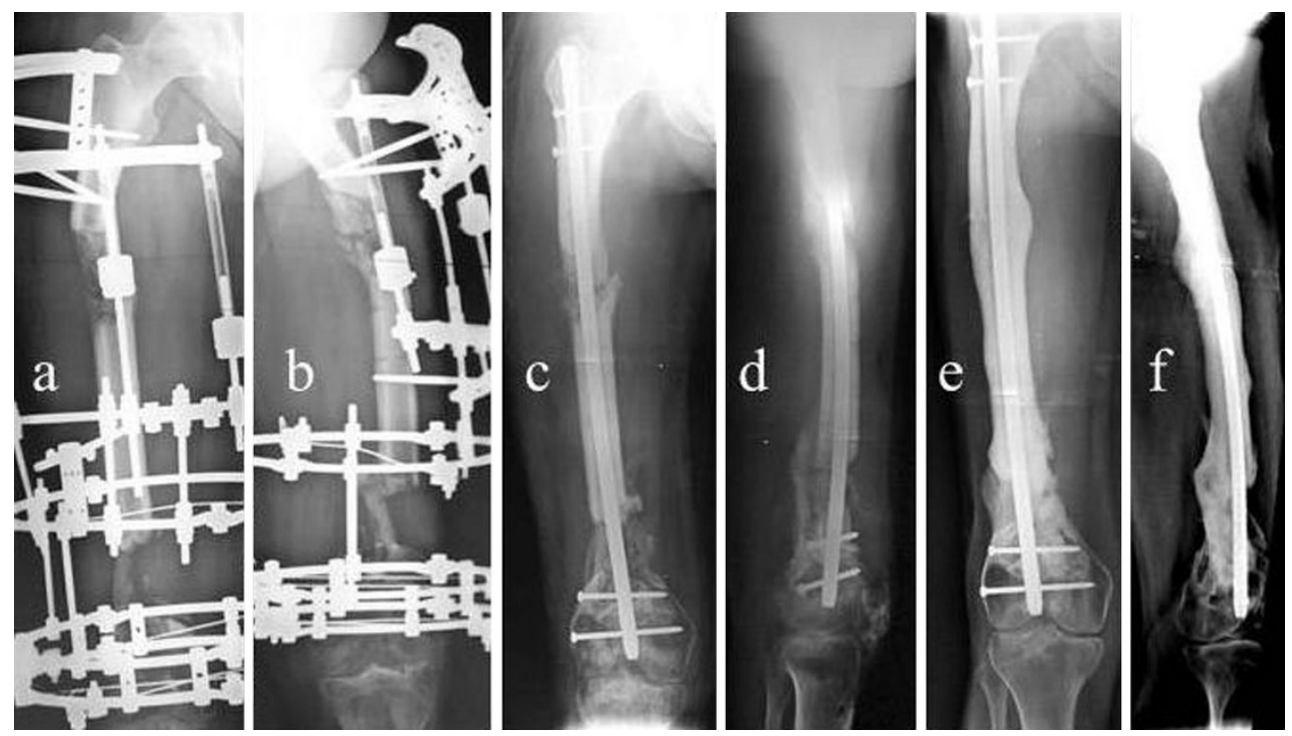

Fig. 2 Case 3: a, b preoperative X-ray; bony bridge in the docking site, arrest of transport, varus, and procurvatus of the regenerated bone, c, $\mathbf{d}$ follow-up 40 days later, e, f follow-up 4 years later

For this case, as well as intramedullary nailing, the docking site was filled with autogenous bone grafts. In two patients (cases 5 and 7, both tibial defects), nailing was carried out for refracture of regenerated bone, which occurred soon after fixator removal. In one patient (case 8, femoral defect), intramedullary nailing was carried out for nonunion of the docking site. In all cases, the fixator was removed prior to nailing and a plaster cast was applied for 10 days. Details of the cases are summarized in Table 1 .

Patients were followed up at 2-month intervals until $\mathrm{X}$-rays showed corticalization with bone thickness equal to that of the bone adjacent to the regenerated bone and/or consolidation of the docking site. The functional outcome measures were recorded, they are as follows: an observable limp, stiffness of the principal joints (defined as $>70^{\circ}$ loss of knee flexion or $>15^{\circ}$ loss of knee extension, $>50^{\circ}$ loss of ankle motion, all as compared with the normal contralateral side), and the ability to fully weight-bearing pain-free. The limb and bone segment was assessed radiologically for axial deformity, union, and for signs of infection after nailing. Fractures after nail removal were noted. The outcome was considered excellent if the patients were fully weightbearing, pain-free, without knee and ankle stiffness, and had a normal aligned limb without need for further surgery after the intramedullary nailing had been performed; good if the patients required more surgery to achieve union; and poor if major complications occurred according to Paley's classification [33]. The patients were asked whether they were satisfied with the procedure or would have preferred primary amputation instead of the multiple procedures undertaken to salvage the limb. No statistical analysis was performed as the number of the cases is small. 
Table 1 Cases

\begin{tabular}{|c|c|c|c|c|c|c|c|c|c|c|}
\hline Case & $\begin{array}{l}\text { Gender } \\
\text { [age } \\
\text { (years)] }\end{array}$ & $\begin{array}{l}\text { Bone, side } \\
\text { (L, left; } \\
\text { R, right) }\end{array}$ & $\begin{array}{l}\text { Open } \\
\text { fracture } \\
\text { Gustilo } \\
\text { I, II, III }\end{array}$ & $\begin{array}{l}\text { Findings } \\
\text { on } \\
\text { culture }\end{array}$ & $\begin{array}{l}\text { Bone } \\
\text { loss } \\
(\mathrm{cm})\end{array}$ & Fixator & $\begin{array}{l}\text { Transport: A, } \\
\text { ascending } \\
\text { technique. } \\
\mathrm{D} \text {, descending } \\
\text { T. DL, double- } \\
\text { level bone T }\end{array}$ & $\begin{array}{l}\text { External } \\
\text { fixator } \\
\text { time } \\
\text { (months) }\end{array}$ & $\begin{array}{l}\text { Regenerated } \\
\text { bone* } \\
\text { IC, R }\end{array}$ & $\begin{array}{l}\text { Docking } \\
\text { site* } \\
\mathrm{C}, \mathrm{N}\end{array}$ \\
\hline 1 & M, 32 & Femur, R & II & Staphylococcus aureus & 10 & Orthofix & DL & 11 & IC & $\mathrm{C}$ \\
\hline 2 & M, 28 & Femur, L & I & Pseudomonas aeruginosa & 6 & Orthofix & $\mathrm{D}$ & 12 & IC & $\mathrm{C}$ \\
\hline 3 & M, 47 & Femur, R & II & Staphylococcus aureus & 9 & Ilizarov & $\mathrm{D}$ & 8 & IC & $\mathrm{N}$ \\
\hline 4 & M, 28 & Femur, L & II & Staphylococcus aureus & 14 & Orthofix & DL & 11 & IC & $\mathrm{N}$ \\
\hline 5 & M, 57 & Tibia, L & I & Staphylococcus aureus & 6 & Ilizarov & A & 9 & $\mathrm{R}$ & $\mathrm{C}$ \\
\hline 6 & F, 25 & Tibia, L & II & Staphylococcus aureus & 18 & Ilizarov & A & 24 & IC & $\mathrm{C}$ \\
\hline 7 & M, 44 & Tibia, L & II & Pseudomonas aeruginosa & 7 & Ilizarov & DL & 10 & $\mathrm{R}$ & $\mathrm{C}$ \\
\hline 8 & M, 28 & Femur, L & I & Pseudomonas aeruginosa & 6 & Ilizarov & A & 13 & $\mathrm{C}$ & $\mathrm{N}$ \\
\hline 9 & M, 31 & Tibia, L & II & Staphylococcus aureus & 10 & Ilizarov & A & 18 & IC & $\mathrm{N}$ \\
\hline
\end{tabular}

*C Consolidation, $N$ nonunion, $I C$ insufficient corticalization, $R$ refracture

\section{Results}

The mean follow-up was 3.9 years (range 2-6). All cases had undergone resection and bone transport for open fractures after road traffic accidents. Complete corticalization of the regenerate column of bone was achieved on average after 6.5 months (range 4-11) after nailing. The length of regenerated bone was checked before and after nailing, and in no case was shortening of regenerated bone observed. None had major complications, neurovascular injuries, joint subluxations or fracture of the regenerated bone. Using the criteria described earlier, eight patients obtained excellent results and only one patient a good result as further surgery was needed; in this case, infection of the tibia occurred 4 months after nailing despite corticalization (case 5, Fig. 3). The nail was removed and the infection treated. The patient was re-examined 3 years after nail removal and was found to be without signs of recurrence. In three other cases, the nail was removed at the patient's request. One patient was found to have knee stiffness that did not require further surgery. All of the patients were satisfied with the procedure, and none expressed a preference for amputation despite the multiple procedures or length of treatment. The patient outcome data are summarized in Table 2.

\section{Discussion}

Several reports in the literature show good results from nailing after or during external fixation. Femoral and tibial nailing with reaming is used commonly after damage control stabilization with external fixation for cases of multiple trauma [16] or open fractures of Gustilo type III $[49,50]$. After the removal of the fixator, intramedullary nailing is carried out in the same operating session or delayed to occur after a period of traction [16, 49] or time in plaster [49, 50], (with or without an interim period of antibiotic therapy) for fear that the pins and wire sites could lead to potential deep intramedullary infections. As early as 1956, Bost et al. [51] described a lengthening technique with an inserted nail, involving external devices and Steinmann pins applied to the same bone segment. Forty years later, Paley et al. [52] presented a series of 32 cases of femoral lengthening using external fixators (Ilizarov or Orthofix) over intramedullary nails ensuring the pins or wires did not contact the nail. At the end of the lengthening period, the fixator was removed and the nail locked. Other cases of lengthening where external fixators were combined with intramedullary nails have also been reported [53-55]. In 39 cases of lengthening, Rozbruch et al. [53] reported one deep infection that was treated by nail removal. The authors attributed the low number of infections partly to the fact that the regenerated bone was well vascularized. In 13 lengthenings with fixators and nailing, Bilen et al. [54] had no cases of infection. In 56 lengthenings with fixators and nails which were either unreamed or only very slightly reamed, Park et al. [55] reported no deep infections and only 13 pin track infections, all which resolved with antibiotics. The literature also contains several reports describing intramedullary nails in bony segments already partially resected due to previous infections. Papineau [56] inserted a nail 2 weeks after surgical debridement and later filled the gap with cancellous bone grafts. Several other authors [57-60] have presented cases of bone transport with fixators and nailing. Raschke et al. [57] have adopted a more cautious approach; in four cases of open tibial fractures of Gustilo types II and III, they first proceeded with debridement and application of external 

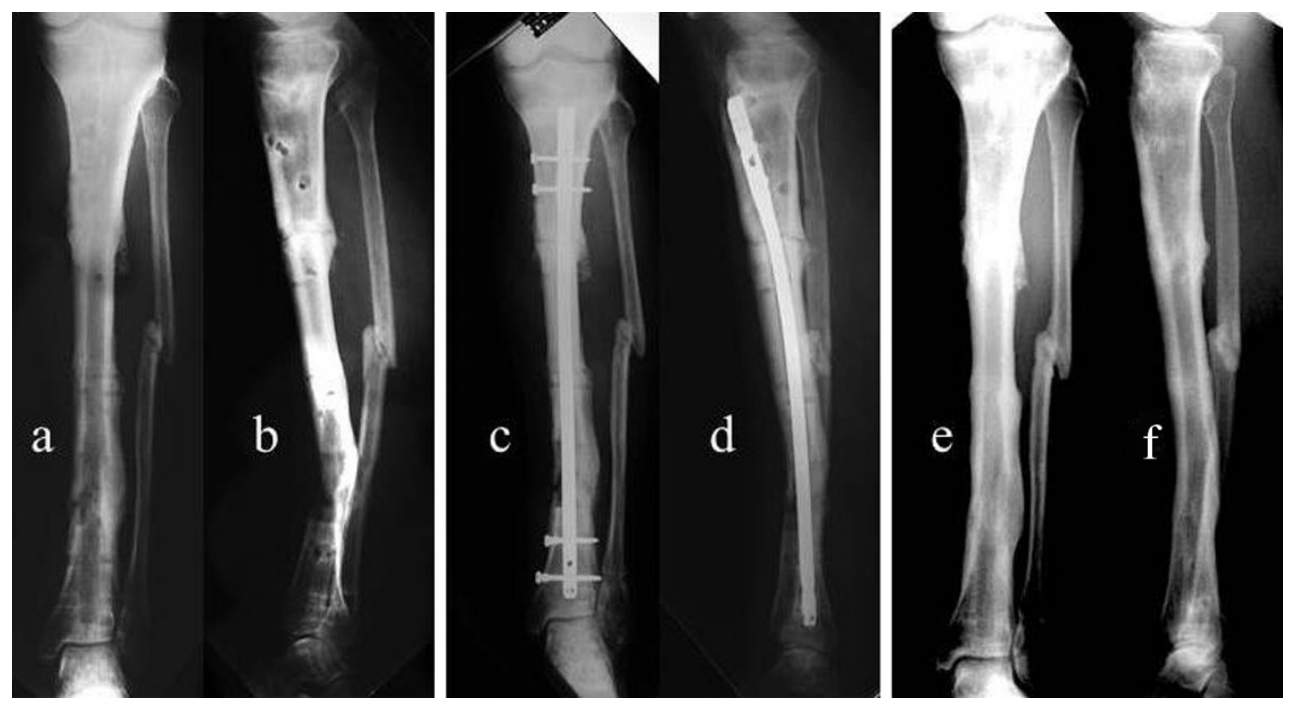

Fig. 3 Case 5: a, b preoperative X-ray, 1 month after the removal of the fixator, c, $\mathbf{d}$ postoperative checkup, e, f follow-up 3 years later

Table 2 Results

\begin{tabular}{|c|c|c|c|c|c|c|c|c|c|}
\hline Case & $\begin{array}{l}\text { Follow-up } \\
\text { (years) after } \\
\text { nailing }\end{array}$ & Limp & $\begin{array}{l}\text { Knee }(\mathrm{K}) \\
\text { or ankle } \\
\text { (A) stiffness }\end{array}$ & $\begin{array}{l}\text { Fully W-B } \\
\text { and pain-free }\end{array}$ & $\begin{array}{l}\text { Axial } \\
\text { deviation }\end{array}$ & $\begin{array}{l}\text { Infection } \\
\text { after } \\
\text { nailing }\end{array}$ & $\begin{array}{l}\text { Consolidation } \\
\text { after nailing } \\
\text { (months) }\end{array}$ & $\begin{array}{l}\text { Removal } \\
\text { of the nail }\end{array}$ & $\begin{array}{l}\text { Fractures } \\
\text { after nail } \\
\text { removal }\end{array}$ \\
\hline 1 & 4 & No & No $\mathrm{K}-\mathrm{A}$ & Yes & No & No & 10 & No & - \\
\hline 2 & 5 & No & No $\mathrm{K}-\mathrm{A}$ & Yes & No & No & 11 & No & - \\
\hline 3 & 4 & Yes & Yes K; No A & No & No & No & 6 & No & - \\
\hline 4 & 3 & No & No $\mathrm{K}-\mathrm{A}$ & Yes & No & No & 8 & No & - \\
\hline 5 & 3 & No & No $\mathrm{K}-\mathrm{A}$ & Yes & No & Yes & 4 & Yes, after 4 months & No \\
\hline 6 & 5 & No & No $\mathrm{K}-\mathrm{A}$ & Yes & No & No & 6 & Yes, after 6 months & No \\
\hline 7 & 6 & No & No K-A & Yes & No & No & 4 & Yes, after 5 years & No \\
\hline 8 & 3.5 & No & No $\mathrm{K}-\mathrm{A}$ & Yes & No & No & 4 & Yes, after 3.5 years & No \\
\hline 9 & 2 & No & No $\mathrm{K}-\mathrm{A}$ & Yes & no & No & 6 & No & - \\
\hline
\end{tabular}

fixators, and after 4-6 weeks inserted locked undreamed intramedullary nails in combination with new monolateral fixators. There were no infections of the medullary canal. In 2002, Lai et al. [15] presented 27 cases of bony transport in femurs and tibias with regenerated bone or docking site problems or refractures. In these cases, with an average of 3-4 weeks after the removal of the fixator, reamed locked nails were inserted. Two cases of infection at the site of the distal docking screws were resolved after nail removal. Eralp et al. [58] presented a series of 17 resections due to chronic osteomyelitis, with antibiotic therapy for 6 weeks and then bone transport with reamed nails and fixators concurrently. They reported three deep infections. In another series of 17 patients, Li et al. [59] used external fixators with reamed nails for bone transport to resolve large defects of the femur which were created after resection for osteomyelitis; the patients were subjected to a 6 -week course of antibiotic therapy before bone transport surgery was performed. They reported 10 superficial pin track infections and one deep intramedullary infection that was treated by the removal of the nail and external fixator and reaming of the medullary canal.

These reports suggest that a nail may be inserted (despite previously infected tissue) if there is interim antibiotic therapy. In our series where bone transport was performed after resection for infection, we inserted the intramedullary nails after an interval of antibiotic therapy. We had one case (case 5) of re-infection after nailing, which we resolved by nail removal after union and antibiotic treatment (Fig. 3). Although some authors [60] believe that the risk of expanding an infection into the medullary cavity increases with the insertion of an intramedullary nail, it is our belief this risk is reduced if the previous site of infection is thoroughly debrided and some time allowed to pass before nailing. This is in order to clear up pin infections that often occur, particularly along 
screws. Kirschner wires, having a smaller diameter, create less serious infections than those produced by pins. Once the infection is treated and resolved, the nail can be inserted after reaming, which serves as a biological stimulator for the corticalization of the regenerate area. Intramedullary reaming for chronic osteomyelitis results may assist in removing the laminar endosteal sequestra of the tibial canal as well as diminishing the intraosseous pressure; the bone is revascularized through an improved periosteal circulation [61-63]. Several authors have also reported their experience with reaming [64-68] showing that reamed bone has considerable osteoblastic potential, equal to that of the iliac crest [66]. Frölke et al. [66] and Wenisch et al. [67] report that human reaming debris is a source of multipotent stem cells that can grow and proliferate in vitro. In a recent review, Brinker et al. [68] stated that in the cases of nonunion, insertion of a second nail after the first promotes healing as long as the canal is reamed again and a larger nail inserted. These considerations may explain the corticalization effect that we found in our cases.

Bone transport is a reliable method for the reconstruction of bone defects in femur and tibia, and remains a safe treatment dealing with defects after resection for bone infection. Similarly, nailing is a good solution for regenerated bone and docking site problems as long as antibiotic therapy is prescribed, and nailing is carried out at least 10 days after the fixator has been removed. Complications due to deep infections are not common and may be resolved.

There are weaknesses in this case series. We acknowledge the small number of the patients and a potential bias due to its retrospective design being major limitations. The literature is limited on the subject of nailing treatment in bone transport complications. This report adds some support to a successful alternative strategy for the treatment for complications of bone transport with a moderate-term follow-up.

Conflict of interest The authors declare that they have not received benefits or funds in support of this study and they have no conflict of interest related to the publication of this manuscript.

Open Access This article is distributed under the terms of the Creative Commons Attribution License which permits any use, distribution, and reproduction in any medium, provided the original author(s) and the source are credited.

\section{References}

1. Mahaluxmivala J, Nadarajah R, Allen PW, Hill RA (2005) Ilizarov external fixator: acute shortening and lengthening versus bone transport in the management of tibial non-unions. Injury Int J Care Injured 36:662-668
2. Reichert JC et al (2009) The challenge of establishing preclinical models for segmental bone defects research. Biomaterials 30:2149-2163

3. Keating JF, Simpsons AH, Robinson CM (2005) The management of fractures with bone loss. J Bone Joint Surg $\mathrm{Br}$ $87: 142-150$

4. Lasanianos NG, Kanakaris NK, Giannoudis PV (2010) Current management of long bone large segmental defects. Orthop Trauma 24:149-163

5. Lin $\mathrm{CH}$ et al (1999) Outcome comparison in traumatic lowerextremity reconstruction by using various composite vascularized bone transplantation. Plast Reconstr Surg 104:984-992

6. Capanna J, Campanacci R, Belot DA et al (2007) A new reconstructive technique for intercalary defects of long bones: the association of massive allograft with vascularized fibular autograft. Long-term results and comparison with alternative techniques. Orthop Clin N Am 38:5-60

7. Lawal YZ, Garba ES, Ogirima MO et al (2011) Use of nonvascularized autologous fibula strut graft in the treatment of segmental bone loss. Ann Afr Med 10(1):25-28

8. Ilizarov GA (1989) The tension-stress effect on the genesis and growth of tissues: part 1 . The influences of stability of fixation and soft-tissue preservation. Clin Orthop Relat Res 238:249-281

9. Saleh M, Rees A (1995) Bifocal surgery for deformity and bone loss after lower-limb fractures. Comparison of bone-transport and compression-distraction methods. J Bone Joint Surg $\mathrm{Br}$ 77:429-434

10. Gordon L, Chiu EJ (1988) Treatment of infected non-unions and segmental defects of the tibia with staged microvascular muscle transplantation of bone-grafting. J Bone Joint Surg Am 70:377-386

11. Aquerreta JD, Forriol F, Canadell J (1994) Complications of bone lengthening. Int Orthop 18:299-303

12. De Backer AI, Mortele KJ, De Keulenaer BL (2004) Picture archiving and communication system: part one: filmless radiology and distance radiology. JBR-BTR 87:234-241

13. De Bastiani G, Aldegheri R, Renzi-Brivio L, Trivella G (1987) Limb lengthening by callus distraction (callotasis). J Pediatr Orthop 7:129-134

14. Paley D (1988) Current techniques of limb lengthening. J Pediatr Orthop 8:73-92

15. Lai KA, Lin CJ, Chen JH (2002) Application of locked intramedullary nails in the treatment of complications after distraction osteogenesis. J Bone Joint Surg Br 84:1145-1149

16. Nowotarski PJ, Turen CH, Brumback RJ, Scaboro JM (2000) Conversion of external fixation to intramedullary nailing for fractures of the shaft of the femur in multiply injured patients. J Bone Joint Surg Am 82:781-788

17. Song HR, Kale A, Park HB, Koo KH, Chae DJ, Oh CW, Chung DW (2003) Comparison of internal bone transport and vascularized fibular grafting for femoral bone defects. J Orthop Trauma 17:203-211

18. Ilizarov GA (1990) Clinical application of the tension-stress effect for limb lengthening. Clin Orthop Relat Res 250:8-26

19. Spinelli R (1989) Segmental bone loss. In: Coombs RG, Sarmiento A (eds) External fixation and functional bracing. Orthotest, London, pp 311-313

20. Tselentakis G, Owen PJ, Naqui SZ et al (2006) Stiffness measurements to assess healing in bone transport: a preliminary report. J Orthop Traumatol 7:84-87

21. Cattaneo R, Villa A, Catagni M, Tentori L (1985) Traitement des pseudarthroses septiques ou non septiques selon la méthode d'Ilizarov en compression monofocale. Rev Chir Orthop 71:223-239

22. Iacobellis C, Berizzi A, Aldegheri R (2010) Bone transport using Ilizarov method: a review of complications in 100 consecutive cases. Strat Traum Limb Recon 5:17-22 
23. Maini L et al (2000) The Ilizarov method in infected nonunion of fractures. Injury 31:509-517

24. Rozbruch RS et al (2006) Simultaneous treatment of tibial bone and soft-tissue defects with the Ilizarov method. J Orthop Trauma 20:197-205

25. Rose RE (2002) The Ilizarov technique in the treatment of tibial bone defects. Case reports and review of the literature. West Indian Med J 51:263-267

26. Lerner A, Ullmann Y, Stein H, Peled IJ (2000) Using the Ilizarov external fixation device for skin expansion. Ann Plast Surg 45:535-537

27. Aldegheri R (1997) Femoral callotasis. J Pediatr Orthop B 6:42-47

28. Caja V, Kim W, Larsson S, Chao EYS (1995) Comparison of the mechanical performance of three types of external fixators: linear, circular and hybrid. Clin Biomech (Bristol, Avon) 10(8):401-406

29. Charalambous CP, Akimau P, Wilkes RA (2009) Hybrid monolateral-ring fixator for bone transport in post-traumatic femoral segmental defect: a technical note. Arch Orthop Trauma Surg 129:225-226

30. Cierny G III, Zorn KE (1994) Segmental tibial defects. Comparing conventional and Ilizarov methodologies. Clin Orthop Relat Res 301:118-123

31. Green SA (1994) Skeletal defects. A comparison of bone grafting and bone transport for segmental skeletal defects. Clin Orthop Relat Res 301:111-117

32. Aronson J, Johnson E, Harp JH (1989) Local bone transportation for treatment of intercalary defects by the Ilizarov technique. Biomechanical and clinical considerations. Clin Orthop Relat Res 243:71-79

33. Paley D (1990) Problems, obstacles and complications of limb lengthening by the Ilizarov technique. Clin Orthop 250:81-104

34. Fischgrund J, Paley D, Suber C (1994) Variations affecting time to bone healing during bone lengthening. CORR 301:31-37

35. Linh HB, Feibel RJ (2009) Tibial lengthening over an intramedullary nail. Tech Orthop 24:279-288

36. Song HR, Cho SH, Koo KH, Jeong ST, Park YJ, Ko JH (1998) Tibial bone defects treated by internal bone transport using the Ilizarov method. Int Orthop 22(5):293-297

37. Wan J, Ling L, Xiang-sheng Z, Zhi-hong L (2013) Femoral bone transport by a monolateral external fixator with or without the use of intramedullary nail: a single-department retrospective study. Eur J Orthop Surg Traumatol 23:457-464

38. Lavini F, Dall'Oca C, Bartolozzi P (2010) Bone transport and compression-distraction in the treatment of bone loss of the lower limbs. Injury, Int J Care Injures 41:1191-1195

39. Wani N, Baba A, Kangoo K, Mir M (2011) Role of early Ilizarov ring fixator in the definitive management of type II, IIIA and IIIB open tibial shaft fractures. Int Orthop 35:915-923

40. Lovisetti G, Sala F, Thabet AM, Catagni MA, Singh S (2011) Osteocutaneous thermal necrosis of the leg salvaged by TSF/Ilizarov reconstruction. Report of 7 patients. Int Orthop 35:121-126

41. Simpson AH, Kenwright J (2000) Fracture after distraction osteogenesis. J Bone Joint Surg Br 82:659-665

42. O'Carrigan T, Paley D, Herzenberg JE (2007) Obstacles in limb lengthening: fractures. In: Rozbruch SR, Ilizarov S (eds) Limb lengthening and reconstruction surgery. Informa Healthcare, New York, pp 675-679

43. Danziger MB, Kumar A, DeWeese J (1995) Fractures after femoral lengthening using the Ilizarov method. J Pediatr Orthop $15: 220-223$

44. Emara KM, Al Ghafar KA, Al Kersh MA (2011) Methods to shorten the duration of an external fixator in the management of tibial infections. World J Orthop 2(9):85-92

45. Brewster MBS, Mauffrey C, Lewis AC, Hull P (2010) Lower limb lengthening: is there a difference in the lengthening index and infection rates of lengthening with external fixators, external fixators with intramedullary nails or intramedullary nailing alone? A systematic review of the literature. Eur J Orthop Surg Traumatol 20:103-108

46. Sun XT, Easwar TR, Manesh S, Ryu JH, Song SH, Kim SJ, Song HR (2011) Complications and outcomes of tibial lengthening using the Ilizarov method with or without a supplementary nail. JBJS Br 93-B:782-787

47. Mora R, Maccabruni A, Bertani B, Tuvo G, Lucanto S, Pedrotti L (2014) Revision of 120 tibial infected non-unions with bone and soft tissue loss treated with epidermato-fascial osteoplasty according to Umiarov. Injury 45:383-387

48. Cierny G III, Mader JT, Penninck JJ (2003) A clinical staging system for adult osteomyelitis. Clin Orthop Relat Res 414:7-24

49. Blachut PA, Meek RN, O'brien PJ (1990) External fixation and delayed intramedullary nailing of open fractures of the tibial shaft. J Bone Joint Surg Am 75:729-735

50. Cosco F, Risi M, Pompili M, Boriani S (2001) External fixation and sequential nailing in the treatment of open diaphyseal fractures of the tibia. Chir Organi Mov 86:191-197

51. Bost FC, Larsen LJ (1956) Experiences with lengthening of the femur over an intramedullary rod. J Bone Joint Surg Am 38:567-584

52. Paley D, Herzenberg JE, Paremain G, Bhave A (1997) Femoral lengthening over an intramedullary nail. A matched-case comparison with Ilizarov femoral lengthening. J Bone Joint Surg Am 79:1464-1480

53. Rozbruch SR, Kleinman D, Fragomen AT, Ilizarov S (2008) Limb lengthening and then insertion of an intramedullary nail. A case-matched comparison. Clin Orthop Relat Res 466:2923-2932

54. Bilen FE, Kocaoglu M, Eralp L, Balci HI (2010) Fixator-assisted nailing and consecutive lengthening over an intramedullary nail for the correction of tibial deformity. J Bone Joint Surg Br 92:146-1152

55. Park HW, Yang KH, Lee KS, Joo SY, Kwak YH, Kim HW (2008) Tibial lengthening over an intramedullary nail with use of the Ilizarov external fixator for idiopathic short stature. J Bone Joint Surg Am 90:1970-1978

56. Papineau LJ (1973) L'excision-greffe avec fermeture retardé délibérée dans l'osteéomyélite chronique. Nouv Presse Med 41:2573-2755

57. Raschke MJ, Mann JW, Oedekoven G, Claudi BF (1991) Segmental transport after unreamed intramedullary nailing. Clin Orthop Relat Res 282:233-240

58. Eralp L, Kocaoğlu M, Polat G, Bas A, Dirican A, Azam ME (2012) A comparison of external fixation alone or combined with intramedullary nailing in the treatment of segmental tibial defects. Acta Orthop Belg 78:652-659

59. Li Z, Zhang X, Duan L, Chen X (2009) Distraction osteogenesis technique using an intramedullary nail and a monolateral external fixator in the reconstruction of massive postosteomyelitis skeletal defects of the femur. Can J Surg 52:103-111

60. Liodakis E, Kenawey M et al (2011) Comparison of 39 posttraumatic tibia bone transports performed with and without the use of an intramedullary rod: the long-term outcomes. Intern Ortho SICOT 35:1397-1402

61. Klemm K, Henry SL, Seligson D (1988) The treatment of infection after interlocking nailing. Technol Orthop 3:54-61

62. Kouzelis AT, Kourea H, Megas P, Panagiotopoulos E, Marangos M, Lambiris E (2004) Does graded reaming affect the composition of reaming products in intramedullary nailing of long bones? Orthopedics 27(8):852-856

63. Lidgren L, Törholm C (1980) Intramedullary reaming in chronic diaphyseal osteomyelitis: a preliminary report. Clin Orthop Relat Res 151:215-221

64. Chapman MW (1998) The effect of reamed and nonreamed intramedullary nailing on fracture healing. Clin Orthop Relat Res 355(Suppl):S230-S238 
65. Hoegel F, Mueller CA, Peter R, Pfister U, Suedkamp NP (2004) Bone debris: dead matter or vital osteoblasts. J Trauma 56:363-367

66. Frölke JP, Nulend JK, Semeins CM, Bakker FC, Patka P, Haarman HJ (2004) Viable osteoblastic potential of cortical reamings from intramedullary nailing. J Orthop Res 22:1271-1275
67. Wenisch S, Trinkaus K, Hild A, Hose D, Herde K, Heiss C, Kilian O, Alt V, Schnettler R (2005) Human reaming debris: a source of multipotent stem cells. Bone 36:74-83

68. Brinker MR, O'Connor DP (2007) Exchange nailing of ununited fractures. J Bone Joint Surg Am 89:177-188 